\title{
Soils and the European Green Deal
}

\author{
Luca Montanarella \\ European Commission, Joint Research Centre (JRC), Ispra (VA), Italy
}

\begin{abstract}
Soils play a central role in achieving sustainable development. The new European Green Deal is addressing all policy areas relevant to sustainable soil management: climate change, biodiversity, agriculture and desertification, including sustainable water management, are necessarily at the core of the European policies. Consistently addressing soil protection across these different policy areas will be the major challenge in front of us in the next years.
\end{abstract}

\section{Introduction}

The new President of the European Commission, Mrs. Ursula von der Leyen, has outlined her priorities 2019-2024, including her vision for a greener Europe: 'Climate change, biodiversity, food security, deforestation and land degradation go together. We need to change the way we produce, consume and trade. Preserving and restoring our ecosystem needs to guide all of our work' (Von der Leyen, 2019). This vision underpins the proposal for a European Green Deal (EGD), striving to be the first climateneutral continent. Becoming the World's first climate-neutral continent by 2050 is the greatest challenge and opportunity of our times. To achieve this, the European Commission presented the European Green Deal, the most ambitious package of measures that should enable European citizens and businesses to benefit from sustainable green transition. Measures accompanied with an initial roadmap of key policies range from ambitiously cutting emissions, to investing in cutting-edge research and innovation, to preserving Europe's natural environment. Achieving sustainable

Correspondence: Luca Montanarella, European Commission, Joint Research Centre (JRC), Directorate D - Sustainable, Resources, Land Resources Unit, Via E. Fermi, 2749, I-21027 Ispra (VA), Italy.

Tel.: +39.0332.785349 - Fax: +39.0332.786394.

E-mail: luca.montanarella@ec.europa.eu

Key words: Water and soil conservation; European Green Deal.

Received for publication: 8 October 2020.

Accepted for publication: 3 November 2020.

(C) Copyright: the Author(s), 2020

Licensee PAGEPress, Italy

Italian Journal of Agronomy 2020; 15:1761

doi:10.4081/ija.2020.1761

This article is distributed under the terms of the Creative Commons Attribution Noncommercial License (by-nc 4.0) which permits any noncommercial use, distribution, and reproduction in any medium, provided the original author(s) and source are credited. soil management in the EU will be crucial for several of the planned actions within the EGD. Sustainable soil management was well defined in 2016 by FAO (FAO, 2017) adopting the Voluntary Guidelines for Sustainable Soil Management. All FAO Members, including EU Member States and the European Commission, endorsed these guidelines. The challenge in front of us is now how to translate these guidelines into actions within the EGD.

\section{Main elements of the European Green Deal rele- vant to soils}

The proposed EGD has several elements (Figure 1) that will lead towards the final goal of a climate-neutral continent. Soils are explicitly mentioned in the farm to fork strategy and in the zero pollution action plan (European Commission, 2019) but are indirectly relevant for achieving climate neutrality in 2050, preserving, and restoring ecosystems and biodiversity. The important role that land degradation and restoration play in preserving terrestrial ecosystems has been well documented in the recent Intergovernmental Science Policy Platform on Biodiversity and Ecosystem Services' (IPBES) Land Degradation and Restoration Assessment (IPBES, 2018). Achieving the SDG target 15.3 of a land degradation neutral world by 2030 will substantially contribute to the perseveration of terrestrial biodiversity.

Soils will therefore play an important role in the future agricultural policy (Farm to Fork strategy), environmental protection (Biodiversity strategy) and climate change (Climate Law).

\section{Soils and agriculture}

European food must remain safe, nutritious and of high quality. It must be produced with minimum impact on nature. To achieve this important goal of the EGD there is the need to implement measures to preserve soil quality and limit soil contamination. Healthy food from healthy soils should be one of the slogans of the EGD. Introducing innovative agricultural practices together with new technology can be the way forward, as envisaged by the mission on soil health and food within the Horizon Europe framework program for research beginning in 2021. A mission in the area of soil health and food will provide a powerful tool to raise awareness on the importance of soils, engage with citizens, create knowledge and develop solutions for restoring soil health and soil functions. It will be important to address the main soil degradation processes that affect the agricultural soils of the EU (EEA, 2019): soil erosion, soil contamination, soil compaction, soil sealing and the loss of soil organic matter and biodiversity continue to be major threats to soil health in Europe. The EU Farm to Fork Strategy will have to consistently address these issues and implement an efficient monitoring system in order to measure progress made in reversing the current negative trend. An effective moni- 
toring, verification and reporting (MRV) system for soil organic carbon in agricultural soils will be necessary in case of accounting of soil organic carbon stocks for climate change mitigation purposes. The proposed components of a suitable MRV system for SOC in agricultural soils (Smith et al., 2019) need to be translated into the elements of an operational MRV system for the EU. This needs to include benchmark sites based on long-term experiments, like in Rothamstead (UK) for calibration, remote sensing tools based on the most recent satellite platforms (EU Copernicus program), ground observations and measurements, like in the LUCAS soil monitoring system and advanced modelling and scenario analysis including spatial data for the final estimates and assessments. This integrated monitoring system will as well deliver the necessary indicators for the new Common Agricultural Policy (CAP) implementation. The necessary innovation and research to fully develop such an integrated system should rely on the establishment of an International Research Consortium on soil organic carbon in agricultural soils. Such an IRC should be open to all interested global players and stakeholders in order to achieve full consensus on the MRV system to be adopted at global scale.

\section{Soils and biodiversity}

Soils host one fourth of the world's biodiversity and provide ecosystem services such as nutritious food, clean drinking water, raw materials and carbon sequestration that are essential to overcome societal challenges like climate change, guaranteeing food security, biodiversity loss, safeguarding human health. Unfortunately, soil degradation is a pervasive, systemic phe- nomenon that occurs in all parts of the terrestrial world and which can take many forms in the EU and globally. Combating land degradation and restoring degraded land is an urgent priority to protect the biodiversity and ecosystem services vital to all life on Earth and to ensure human well-being. Land cover change and management intensity significantly affect soil condition and soil biodiversity in the EU. Progress in the remediation of polluted soils is slow. Despite recent reductions in soil sealing, fertile soils and soil biodiversity continue to be lost by land take. On intensively managed land, soil biodiversity is endangered and soil carbon depleted. Soil loss because of erosion is still significant and results in relevant economic costs to the European citizens (Panagos et al., 2018). In order to revert this negative trend in land degradation there is the need to device a comprehensive land restoration program as recommended by IPBES (IPBES, 2018). This should include a commitment by the European Union:

- To protect soil functions, particularly fertility, and achieve land degradation neutrality in the EU, addressing specific drivers that reduce soil biodiversity, carbon storage and fertility and implementing extensively sustainable soil management practices;

- Substantially increase efforts to reduce soil erosion and increase soil organic matter, and to enhance the integration of land use aspects into decision-making at all levels of government, supported by the adoption of targets on soil and on land;

- EU policies take into account their direct and indirect impact on land use in the EU and globally, and the rate of land take is well on track with an aim to achieve no net land take by 2050;

- To progress considerably in identification and remediation of polluted sites.

All of these positive actions were already clearly outlined in

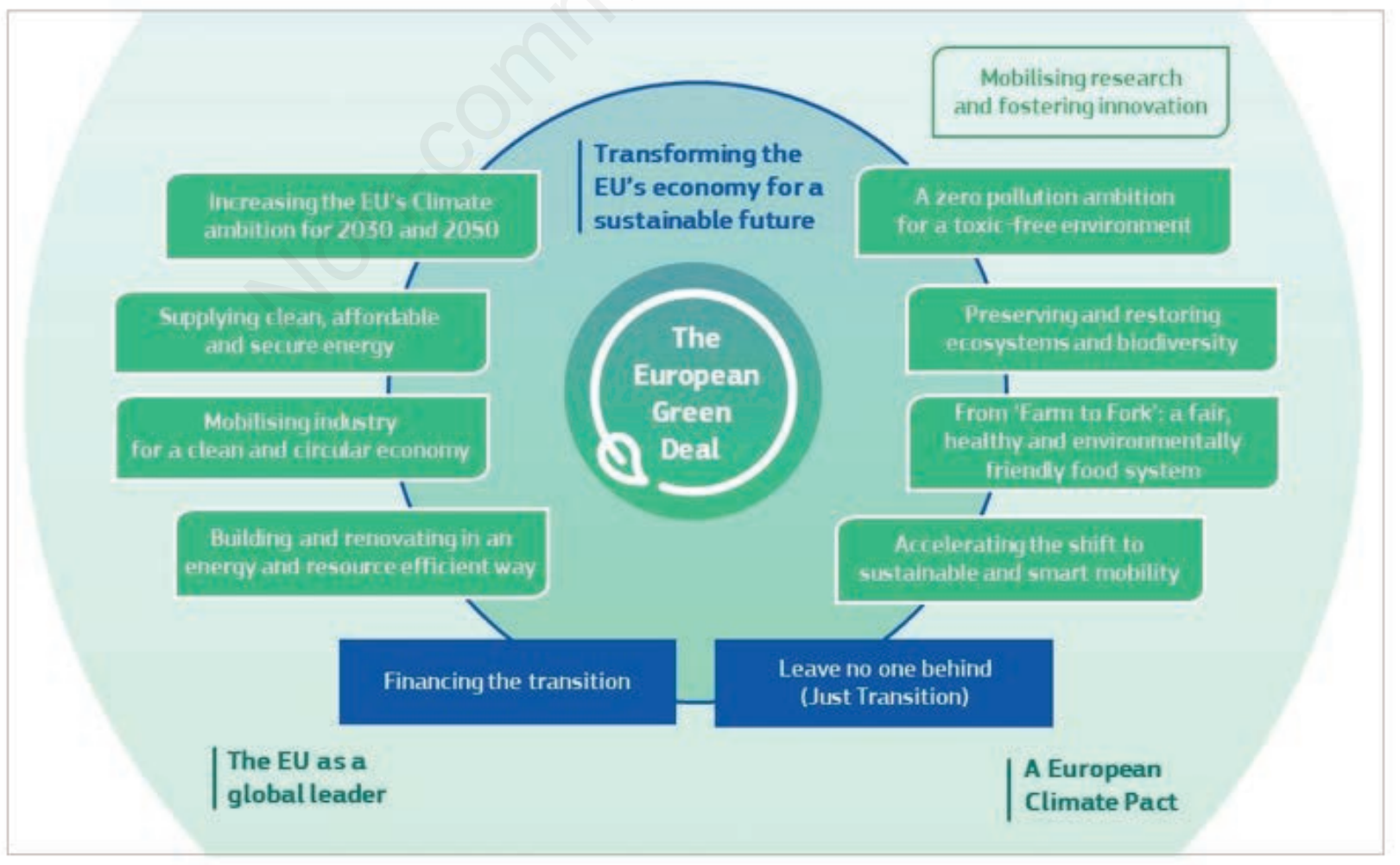

Figure 1. The various elements of the European Green Deal (COM(2019) 640 final). 
the EU Soil Thematic Strategy adopted by the European Commission in 2006 (European Commission, 2006). 14 years after the adoption of the strategy there is the need for a clear and objective assessment of the reasons for the failure of the proposed strategy in achieving full soil protection in the EU. A new strategy is needed based on the new scientific evidence and including few, measurable targets with a clear timeline. A new EU Soil Observatory that will be collecting the policy relevant data and indicators for the regular assessment of the progress made should closely monitor the new strategy.

\section{Soils and climate change}

In order to achieve climate neutrality by 2050 there will be the need to use the full potential of European soils for mitigation and adaptation strategies. Increasing the soil organic carbon pool in agricultural soils by implementing sustainable soil management practices will contribute to the final achievement of this ambitious goal. Halting land degradation and restoring degraded lands, as recommended by IPBES (IPBES, 2018) and IPCC (IPCC, 2019), should be at the core of such a strategy. Achieving land degradation neutrality by 2030 (SDG target 15.3 ) should be a pre-condition for the later achievement of a climate neutral continent in 2050. Plenty of land restoration initiatives and programs are possible in the EU. There will be the need for a coherent action plan on how to achieve land degradation neutrality, including the financial mechanisms that will allow the massive investments in land restoration that are needed. As already pointed out by the recent evaluation by the European Court of Auditors (ECA, 2018), the EU is still lacking a coherent approach for combating land degradation and desertification, with only one EU member state (Italy) that has presented a land degradation neutrality target setting program as recommended by the United Nations Convention to Combat Desertification (UNCCD).

Land restoration results in a measurable increase of soil organic carbon. Healthy soils store large quantities of carbon (C) in the form of soil organic carbon (SOC). For this reason, SOC is included as a metrics for the regular assessment of land degradation in reporting for SDG target 15.3. Soils constitute the largest terrestrial carbon pool: an estimated total of 2,344 Gt C, more than the sum of carbon contained in the atmosphere and vegetation (Stockmann et al. 2013). Soils perform crucial functions in the global carbon balance and recognition of the importance of soils and their sustainable management for addressing climate change adaptation and mitigation is increasing. Recent discussions under the Koronivia Joint Work on Agriculture (KJWA) particularly highlighted the positive role of soils for climate change adaptation and mitigation, agriculture and food security. There exists substantial scientific and practical evidence of how sustainable soil management (SSM) can provide multiple benefits for the environment, people and livelihoods. SSM preserves and increases SOM, a key element of soil health, which regulates many soil functions, including carbon storage in the form of SOC. In this way, SSM supports the retention and enhancement of carbon stocks in soils and thus climate change mitigation, while generating benefits for agriculture, food security and nutrition, provision of ecosystem services, climate change adaptation, and advancing multiple sustainable development goals (SDGs). Investing in SSM constitutes a cost-effective and feasible climate change mitigation option, which, at the same time, enhances soil health and climate resilience. 128 countries include the Agriculture, Forestry and Land Use sector in their pledges for the Paris Agreement. Limiting warming to $1.5^{\circ} \mathrm{C}$ will require the use of 'negative emissions technologies' - methods that remove $\mathrm{CO}_{2}$ from the atmosphere such as soil organic carbon sequestration (Soussana et al., 2019). Soil organic carbon sequestration (SCS) is a major mitigation option. Up to $1.4 \mathrm{Gt} \mathrm{C}$ could be stored annually in agricultural soils (after IPCC, 2007, 2014). About $20 \%$ of the mitigation from SCS is achieved at negative cost and $80 \%$ below US $\$ 100 / \mathrm{tCO}_{2}$ eq making SCS a low-cost mitigation option. It requires conserving carbon stocks, storing carbon in agricultural landscapes both in soil organic matter and in biomass through agroforestry, reducing $\mathrm{CO}_{2}$ emissions from drained peatlands and wetlands and better recycling organic carbon through improved circularity and lifecycle of urban and agri-food industries organic wastes, thereby contributing to the bioeconomy.

SOC conservation and sequestration also have multiple cobenefits for food security, climate change adaptation, land degradation neutrality (an objective agreed by the UNCCD), desertification, biodiversity and water resources as shown by the latest IPCC Special Report on Climate Change and Land. Further, SOC content is a target (15.3) of the life on land Sustainable Development Goal 15. Both for UNCCD and for UNFCCC, countries are requested to report on SOC status. However, only a few countries have the capabilities and methods to monitor agricultural soil carbon with country specific methods.

While there is considerable private and public interest in soil carbon and health, adoption of soil enhancing agricultural practices appears to be slow. Farmers from several world regions see the main barriers to adoption as socio-economics (e.g. additional costs are too high; lack of funds to access technology or machinery; farm extension services do not have knowledge and capacity). Overcoming these barriers requires a strengthened knowledge base and advisory services, improved awareness in the public, increased availability of indicators and tools, as well as financial support for agricultural transition and payments for soil carbon and other ecosystem services.

Although barriers may vary with national circumstances, stakeholders and farmers from different world regions have similar views on the major barriers preventing an increased adoption of soil carbon sequestration and soil health enhancing practices.

\section{Soil and water nexus}

Any soil related policy strategy cannot be considered in isolation from the close interdependence between soil and water management. Although it seems intuitive that soil and water need to be considered jointly in research and policy-making addressing agricultural production and sustainable livelihoods, there is still plenty of evidence that these two topics are often discussed separately. In hydrology soil is often reduced to a transfer zone ignoring the significance of soil when extending the perspective from the flow of pure water towards matter fluxes which is critical for the sustainability of terrestrial systems. In soil science, on the other hand, hydrological processes are often reduced to boundary conditions ignoring the importance of water dynamics within the unsaturated zone for all kinds of biogeochemical processes. Beyond the scientific perspective, the separation of water and soil issues which can lead to counter-productive rural development policies. What is critical is to continue re-enforcing integrated research programmes but most importantly to ensure that policies are informed by the results of these research activities.

Soil and water are two of the principle resources for agricultur- 
al production and they need to be addressed together for effective rural development. Yet, in many circumstances, these are not considered together, in particular since these resources can fall under different line ministries at the national level. At the international level, many organizations are either water or soil (land) bodies and few address the two resources jointly. To achieve sustainable livelihoods both in rural areas but also indirectly in urban areas, we need to place more emphasis on tackling simultaneously soil and water issues for agricultural development but also for environmental hazard mitigation. This perspective is at the core of the only global multilateral environmental agreement addressing both, soil and water, the United Nations Convention to Combat Desertification (UNCCD).

This convention is addressing land degradation and is the main implementing tool for achieving by 2030 a land degradation neutral world, as requested within the SDG 15 by target 15.3.

Achieving such a world by 2030 requires a major shift in the overall human behaviours, starting with the consumption habits. As highlighted in the IPBES Land Degradation and Restoration Assessment (IPBES 2018), we need to address land degradation and engage in major land restoration efforts if we want to reverse the negative trend. Ten strategies have been proposed to overcome the policy barriers to achieve land degradation neutrality, and thus transform the effectiveness of land protection and restoration (Willemen, 2020):

1. Recognize that the benefits generated by healthy and productive land are a global good.

2. Set clear, quantifiable, legally binding and ambitious targets to ensure that policies to halt and reverse land degradation match the scale and urgency of the problem.

3. Routinely collect and evaluate information on the state of land.

4. Promote local action to tackle land degradation based on local contexts and needs.

5. Build on all pertinent knowledge sources, not exclusively on conventional science.

6. Take into account all the substantive costs and benefits when making decisions that impact on land.

7. Reduce the human demands for services delivered by land to match the capacity of the land to supply those services sustainably.

8. Encourage responsible trade and consumption.

9. Strengthen judicial institutions for environmental action by citizens.

10. Re-evaluate what it means to live well.

\section{Conclusions}

Soils play a central role in achieving the Sustainable Development Goals (SDGs) by 2030 (Bouma et al., 2019). For Europe, this means that soils will have to be included as a key element of the proposed European Green Deal (EGD). Especially soils play a key role in achieving the ambitious European target of a climate neutral EU by 2050 . As a major carbon sink they play an important role in mitigating greenhouse gas emissions and therefore should be an important element of the new EU Climate Law. In addition, they hold a large biodiversity pool (Jefferey et al., 2010) and therefore need to be included in the new EU Biodiversity Strategy. Finally, soils are the foundation of agriculture, and therefore will have to play an important role in the EU Farm to Fork Strategy. Incorporating a coherent sustainable soil management framework within all three of these strategies will be challenging, given the necessary trade-offs between sometimes contradicting goals and targets. A coherent framework could be a revised EU Soil Thematic Strategy taking into account the goals and ambitions of the European Green Deal.

\section{Highlights}

- Soils play a central role in achieving the goals of the European Green Deal.

- Sustainable soil management is a cross-cutting issue relevant to several policy areas addressed by the European Green Deal, such as climate change, biodiversity, agriculture, food safety.

- Human health and wellbeing are closely connected with soil health and sustainable soil management.

\section{References}

Bouma J, Montanarella L, Evanylo G, 2019. The challenge for the soil science community to contribute to the implementation of the UN Sustainable Development Goals. Soil Use Manage. 00:1-9.

ECA, 2018. Combating desertification in the EU: a growing threat in need of more action, Special Report No 33, European Court of Auditors, Luxembourg. Available from: https://www. eca.europa.eu/Lists/ECADocuments/SR18_33/SR_DESERTIFICATION_EN.pdf

EEA (European Environment Agency), 2019. The European environment - state and outlook 2020. doi: 10.2800/96749.

European Commission, 2006. Communication from the Commission to the Council, the European Parliament, the European Economic and Social Committee and the Committee of the Regions - Thematic strategy for soil protection (COM(2006) 231 final).

European Commission 2019. The European Green Deal. $\operatorname{COM}(2019) 640$ final.

FAO, 2017. Voluntary Guidelines for Sustainable Soil Management Food and Agriculture Organization of the United Nations Rome, Italy. Available from: http://www.fao.org/3/abl813e.pdf

IPBES, 2018. Land degradation and Restoration assessment, IPBES Secretariat, Bonn, Germany.

IPCC, 2019. Climate Change and Land: an IPCC special report on climate change, desertification, land degradation, sustainable land management, food security, and greenhouse gas fluxes in terrestrial ecosystems [P.R. Shukla, J. Skea, E. Calvo Buendia, V. Masson-Delmotte, H.-O. Pörtner, D. C. Roberts, P. Zhai, R. Slade, S. Connors, R. van Diemen, M. Ferrat, E. Haughey, S. Luz, S. Neogi, M. Pathak, J. Petzold, J. Portugal Pereira, P. Vyas, E. Huntley, K. Kissick, M. Belkacemi, J. Malley, (eds.)]. [In press].

Jefferey S, Gardi C, Jones A, Montanarella L, Marmo L, Miko L, Ritz K, Peres G, Römbke J, van der Putten WH (Eds.), 2010. European Atlas of Soil Biodiversity. European Commission, Publications Office of the European Union, Luxembourg. EUR 24375 EN, 128pp.

Panagos P, Standardi G, Borrelli P, Lugato E, Montanarella L, Bosello F, 2018. Cost of agricultural productivity loss due to soil erosion in the European Union: From direct cost evaluation approaches to the use of macroeconomic models. Land Degrad. Develop. 29:471-84.

Smith P, Soussana J-F, Angers D, Schipper L, Chenu C, Rasse DP, 
Batjes NH, van Egmond F, McNeill S, Kuhnert M, AriasNavarro C, Olese JE, Chirinda N, Firnara D, Wollenberg E, Álvaro-Fuentes J, Sanz-Cobena A, Klumpp K, 2019. How to measure, report and verify soil carbon change to realize the potential of soil carbon sequestration for atmospheric greenhouse gas removal. Glob Change Biol. 00:1-23.

Soussana JF, Lutfalla S, Ehrhardt F, Rosenstock T, Lamanna C, Havlík P, Richards M, Wollenberg E, Chotte J-L, Torquebiau E, Ciais P, Smith P, Lal R, 2019. Matching policy and science: Rationale for the ' 4 per 1000 -soils for food security and climate' initiative. Soil Tillage Res. 188:3-15.

Stockmann U, Adams MA, Crawford JW, Field DJ, Hanakaarchchi N, Jenkins M, Minasny AB, de Remy de Courcelles V, Singh K, Wheeler I, Abbott L, Angers DA, Baldock J, Bird M, Brookes PC, Chenu C, Jastrow JD, Lal R, Lehmann J,
O'Donnell AG, Parton WJ, Whitehead D, Zimmermann M, 2013. The knowns, known unknowns and unknowns of sequestration of soil organic carbon. Agric. Ecosyst. Environ. 164:80-99.

Von der Leyen U, 2019. A Union that strives for more. My agenda for Europe. Available from: https://ec.europa.eu/commission/ sites/beta-political/files/political-guidelines-next-commission_en.pdf

Willemen L, Barger NN, Brink Bt, Cantele M, Erasmus BFN, Fisher JL, Gardner T, Holland TG, Kohler F, Kotiaho JS, von Maltitz GP, Nangendo G, Pandit R, Parrotta JA, Potts MD, Pince SD, Sankaran M, Brainich A, Montanarella L, Scholes R, 2020. How to halt the global decline of lands. Nat. Sustain. 3:164-6. 